\title{
POETICA DE LA TRASCENDENCIA: APROXIMACIONES METODOLÓGICAS
}

\author{
Miguelina Soifer \\ Universidade Federal do Paraná
}

Estructuras poéticas y los Regimenes de Gilbert Durand. - EI Régimen de la'trascendencia extrahumana. - Régimen Nocturno y estrucuturas místicas. - La tensión interiorizante del impulso mistico.

- La coherencia de ambos enfoques. - Los 'gestos' poéticos. - Aproximaciones metafísicas. - Aproximación artistica en G. Durand: la retórica. - Poética de la trascendencia y epifanía.

\section{ESTRUCTURAS POÉTICAS Y LOS REGIMENES DE GILBERT DURAND.}

Al referir el ámbito de la trascendencia a sus motivaciones imagina. tivas, al verificar la legitimidad metodológica que lleva al desvendamiento de ese ámbito, la teoria de Gilbert Durand se reviste de gran interés por las coincidencias entre el esquema estructural literario que analizamos, especificamente con relación a dos actitudes an imicas ${ }^{1}$ : el impetu ascensional y el refugio en la interioridad - y los "Regimenes" de clasificación de lo imaginante en la citada obra.

En su perspectiva antropológica Durand estudia las representaciones simbólicas suscitadas por los reflejos dominantes en la especie humana, es decir "el trayecto entre motricidad y representación" ciendo suyos los postulados betcheverianos, parte de "gestos posturales", resortes biofísicos, fundamentadores de los esquemas imaginativos que se agruparán en prototipos o "arquetipos" (en el lenguaje de Jung), imágenes primordiales o constelaciones de imágenes alrededor de centros

\footnotetext{
'Les structures anthropologiques de l'imaginaire. Paris. Bordas, 1969.

- Las citaciones de Durand en español, han sido traducidas del original francés por la autora.

Letras, Curitiba (33) $163179 \cdot 1984$ - UFPR 
organizadores, válidos para todas las manifestaciones imaginativas humanas: estos elementos se agrupan finalmente en Regímenes de la imagen, la más amplia y comprehensiva de las categor ias clasificantes, siendo estos dos Regimenes el Diurno y el Nocturno. El primero, caracterizado por la aprehensión angustiante del devenir $y$ antitéticamente por la recuperación luminosa de esa reacción negativa, reconquista victoriosa del destino y la muerte, buscada a nivel de lo sobrehumano, lo trascendente o lo esencial en su pureza; el Régimen Nocturno buscando $y$ valorizando la luz en el interior de la misma noche, ahi vislumbrando la aurora; régimen eufemístico que sintetiza las aspiraciones transcendentes con las intuiciones del devenir, encuentra un antídoto del tiempo en la cálida intimidad de la sustancia o en las constantes rítmicas que escanden fenómenos $y$ accidentes, $y$ al dominar $y$ medir el flujo temporal inexorable, resuelve en conciliación "el terror ante el tiempo que huye" y la "esperanza de vencer al tiempo".

El Régimen Diurno, que Durand caracteriza especificamente como el de la "trascendencia extrahumana", se anuncia por eso en posible convergencia a la poética; en efecto, de los esquemas que lo constituyen, el esquema ascensional con su impulso verticalizante homólogo de elevación moral, espiritual y hasta metafísica, reencuentra los resortes de la proyección poética hacia el ámbito epifánico que se analiza en este estudio, proyección centrada en el anhelo de transcendencia. Algunas figuraciones tipicas de la expresión místico-poética caracterizan también al esquema ascensional durandiano, por ejemplo el simbolismo angélico, que citamos en los poemas de "Sobre los ângeles" de Rafael Alberti ${ }^{2}$, circunscribiéndose en gran parte la motivación de esas figuraciones exactamente a la "ascesis catártica de la ascensión alada" aludida por Durand cuando afirma, al caracterizar la diurnidad, que "toda trascendencia se acompaña de métodos de distinción y purificación". Otro proceso coincidente aparece cuando Durand afirma que "la verticalidad se opone a la teriomorfía temporal por el ala y el ave, construyendo los sueños de rapidez, ubicuidad y vuelo contra la fuga mordiente del tiempo". Este vuelo imaginado aparece entre los rasgos expresivos de la plasmación poético-mistica (por ejemplo en la poesía de San Juan de la Cruz) dominada por tal tensión a la infinitud - también una fuga de lo "temporal" a lo divino - que el mismo Durand asocia a un platonicismo estructural de toda la literatura de Occidente:

${ }^{2}$ SOIFER, M. Le expresión misticopótica en Alberti, Jimenez y Cortázar. Curitiba, 1977. Tese, Titularidade, Universidade Federal do Paraná. 
"De même

Rougemont s'ingénie à retrouver le dualisme des métaphores de la nuit et du jour chez les troubadours, les poètes mystiques du soufisme, le roman breton (. . .) et enfin dans la poésie mystique de St. Jean de la Croix. Selon Rougemont, ce dualisme d'inspiration cathare structurerait toute la littératura d'Occident, irrémediablement platonicien$n e^{\prime \prime}$. (p. 69).

El mismo Durand refiere este criterio platónico a su Regimen diurno, que caracteriza como "el trayecto representativo que va desde la primera y confusa glosa imaginativa calcada sobre los reflejos posturales, hasta la argumentación de una lógica de la antítesis y del "huir de aqui' platónico". (p. 215)

Otro principio de la representación que en la diurnidad durandiana se vincula estrechamente al verticalismo ascensional es el de los simbolos espectaculares, que reafirman un isomorfismo luz-altura, o luminoso-celeste. Como signo de una mística invertida, de verticalidad descendente, estudiamos en la prosa de Saint Exupéry el binomio luz-valor, cuya génesis se da en la visión del aviador, proyectada no de lo terrestre a lo celeste, sino del plano estelar a la luz terrestre, humana, del hogar y de las ciudades, que en la soledad de los espacios aéreos adquiere el precioso valor de una meta mística. ${ }^{3}$

En cuanto a la caracterización antropológica más abarcante del Régimen diurno como régimen de la antitesis, lo correspondiente en plano de la Poética, esta figura "retórica" (Durand) es vital para el discurso místico-poético donde se la estudia como uno de los procedimientos estil ísticos infaltables para la expresividad de lo indecible, en su ruptura con los encadenamientos lógicos: la antítesis metafísica y sobrenatural del lenguaje místico se expresa espontáneamente en la antítesis poética, donde la estridencia de la contradicción nos hace abandonar el plano lingü ístico y vislumbrar la inefable experiencia.

\section{Régimen Nocturno y "estructuras místicas" en Durand}

Una aproximación evidente de la Poética de la trascendencia al Régimen Nocturno, reside en las "estructuras misticas" (asi denominadas por Durand e incluídas, al lado de los símbolos de inversión y de los símbolos de intimidad, en ese régimen). Entre las estructuras místicas estudia el autor la viscosidad eufemística, que en todo adhiere a

${ }^{3}$ SOIFER, M. La expresión místico-postica: Valéry y San Juan de la Cruz. Curitiba, Editora da Universidade Federal do Paraná, 1983. p. 118. 
los objetos y a su imagen, rehusando separar, cortar y someter el pensamiento a la implacable antítesis diurna, adhiriendo al aspecto concreto, colorido, e intimo, al conocimiento vital de los seres, descendiendo imaginativamente a su intimidad; son las estructuras gliscomórficas, que encuentra Durand en el arte de Van Gogh como viscosidad del tema $Y$ de los elementos representativos, $y$ hasta en su escritura pictórica. Pues bien, al definir la dimensión mistica de la poesía valéryana en su visión de la naturaleza, citábamos un pasaje de La jeune parque que bien puede ilustrar el estilo aglutinante de Van Gogh en su régimen misticonocturno, como ejemplo de la escritura pictórica toda en vírgulas $\gamma$ torbellino, del pintor de los girasoles; al mismo tiempo, al profundo dinamismo, a la sensación de intenso movimiento que anima todo su universo, y hasta la más estática naturaleza muerta. Es lo que caracteriza también en Valéry a esa "flottante forêt" mística y vangoghiana podemos ahora calificarla - con que ilustrábamos el dinamismo, en los rasgos de "retorcimiento $y$ estiramiento barroco que la sed de alturas infunde a la naturaleza en la expresión mistica" - deciamos:

Les arbres regonflés et recouverts d'écailles
Chargés de tant de bras et de trop d'horizons,
meuvent sur le soleil leurs tonnantes toisons,
Montent dans l'air amer avec toutes leurs ailes.
De feuilles par millers qu'ils se sentent nouvelles. .
N'entends-tu pas frémir ces noms aériens,
O Sourde!. . Et dans l'espace accablé de liens,
Vibrant de bois vivace infléchi par la cime,
Pour et contre les dieux ramer l'arbre unanime,
La flottante forêt de qui les rudes troncs
Portent pieusement à leurs fantasques fronts,
Aux déchirants départs des archipels superbes,
Un fleuve tendre, ô mort, et caché sous les herbes?

$(\text { versos } 230-242)^{4}$

La tensión a lo infinito infunde un dinamismo continuo a los elementos: "arbres regonflés", "chargés de tant de bras", "meuvent sur le soleil leurs tonnates toisons", "montent dans l'air", "leurs ailes", "espace accablée de liens/vibrant de bois vivace infléchi par la cime", "frémir" "ramer l'arbre". "la flottante forèt", "déchirants départs". Texto significativo donde tienen expresión también las preposiciones sur $y$ avec, caracterizadoras para Durand de lo gliscomórfico: "Meuvent sur

${ }^{4}$ SOIFER, Le expresión: Valery ....p. 115. 
le soleil", "montent. . . avec toutes leurs ailes". Enfin, todo el movimiento místico, participante, que por sí solo ilustra este principio imaginante estudiado por Durand se condensa en este bello verso:

"Tout I'univers chancelle et tremble sur ma tige".

\section{La tensión interiorizante del impulso místico}

Una coincidencia notable entre la clasificación durandiana y la teoría de la expresión mistica, reside en el reconocimiento de una tensión interiorizante del impulso místico, caracterizada en nuestra teoría por las dos posibilidades direccionales de este impulso, calificadas transfusiva y concentrativa, respectivamente. Durand se refiere al definir su Régimen nocturno, (esquema místico o antifrásico) a uma integración afectiva en el espacio imaginante que se realiza en sentido de "descenso e intimidad profundizante".

"C'est à une transmutation directe des valeurs d'imagination que nous invite la descente, et Harding cite les gnostiques pour qui 'monter ou descendre cela revient au même', associant à cette conception de l'inversion la doctrine mystique de Blake pour laquelle la descente est aussi un chemin vers l'absolu" (230)

Este descenso profundizante coincide, por lo tanto, con una de las posibilidades direccionales del impulso místico:

"En San Juan de la Cruz es un movimiento de trans-fusión: no hay en sus poemas duda ni evasion, todo es certidumbre, "via recta", éxtasis (. . .) Cuanto al impulso de la mistica valeryana, se define por un movimiento de concentración. Tal concentración implica un encauzamiento de la intencionalidad mística hacia la interioridad del ser, como solución para la dicotomía "facultad de trascender - sensualidad humana".

"La poesia de Valéry expresa su intuición del ser como potencialidad de transcendencia y como plenitud de sensitividad, y la conciencia de tal potencialidad, que fascina y tortura al poeta, genera todo el cauce místico de la expresión. Aprehendida en sus limitaciones, es proyectada en contraste conflictivo con la plenitud sensible, para Valéry inherente a la naturaleza humana"s.

${ }^{5}$ SOIFER, La expresión: Valéry ... . p. 96. 
Es entre los símbolos de la inversión donde Durand estudiará la tesión interiorizante:

"Par exemple le but que se proposent les constellations que nous allons étudier ne sera plus l'ascension du sommet mais la pénétration d'un centre, et aux techniques ascensionnelles vont succéder des techniques de creusement, /.../ comme conservant un accent de l'enthousiasme ascensionnel, mais aussi le sentier difficile méandreux et labyrinthique, le "durohanna" que laissent pressentir les images angoissantes du gouffre, de la gorge et de l'abime". (p. 226)

La angustia del abismo, del precipicio, está justamente en la trayectoria mística de la Joven Parca, y en otros de sus personajes-símbolo: La Pythie, Le Rameur, por ejemplo. "El éxtasis en el misticismo valéryano se concibe como una experiência ardiente $y$ desordenada, pero su misticismo autoconcentrativo es también de linea anticlimática, si no por la beatitud de la fusión propia del Santo, por el apagamiento interior, con tintes melancólicos que la imposibilidad de total trascendencia causa en el poeta. En la Pythie esa facultad es sentida como marca angustiante, sufrimiento sobrehumano que le ha sido impuesto y del cual intenta libertarse. La Joven Parca alcanza efimeras transcendencias y se desgarra en sus impulsos hacia lo invisible, que refluyen finalmente hacia su interioridad.

\section{La coherencia de ambos enfoques}

Cada coincidencia de argumentaciones detectada entre la teoría durandiana y la Poética, puede suponer una nueva comprobación de la validad metodológica de esta última, pues formuladas a partir de enfoques diversos, uno de ámbito antropológico, otro analítico-literario, su aproximación resulta signo de su reciproca coherencia.

A las estructuras semejantes que se acaban de enumerar puede agregarse la aproximación que supone citar a los mismos poetas para caracterizar, respectivamente, los fundamentos deductivos de la Poética de la trascendencia ("La expresión místico-poética. Valéry y San Juan de la Cruz") y la categoría o Régimen diurno:

Le Regime Diurne de l'image se définit donc d'une façon génerale comme le regime de l'antithèse. Ce manichéisme des images diurnes n'a point échappé à ceux qui ont abordé l'étude approfondie des poètes de la lumière. (. . .) De même Rougemont s'ingénie à retrouver le dualis- 
me des métaphores de la nuit et du jour chez les troubadours, les poètes mystiques du soufisme, (. . .) et enfin dans la poésie mystique de Saint Jean de la Croix.

(. . .) De même Guiraud relève excellement l'importance des deux mots clefs les plus fréquents chez Valéry: "pur" et "ombre" qui forment le portant du décor poétique" (p. 69)

La coherencia de ambos enfoques, el antropológico y el literario, así se destaca, aunque en el segundo se parta de concordancias expresivas, de la configuración formal, convergente en mundos poéticos alejados cronológica, espacial y espiritualmente - exactamente como lo son los de San Juan y Valéry - para inducir una función de lo poético. Se parte, diríamos, de un "gesto poético" semejante definido por el impulso afectivo imaginativo del mismo signo en ambos autores, aunque de proyección a metas espirituales divergentes: el impulso de trascender hacia Dios y hacia la esencia poética respectivamente - para caracterizar el territorio poético de la trascendencia, mientras la incursión antropológica de Durand parte de lo que el autor llama "gestos poturales", que son los imperativos biofisicos de la motricidad y la imagen.

Como vimos hasta ahora, en la caracterización durandiana de las estructuras imaginativas debiamos fijarnos particularmente en el esquema ascensional con su dimensión de elevación y dicotomía trascendente, perteneciente al Régimen Diurno; $v$, por otro lado, en el esquema místico o antifrásico, que en su Régimen Nocturno encuentra integración afectiva en el espacio imaginante, en una dirección de descenso e intimidad profundizante, esquema místico y esquema ascensional encuadrados en regímenes divergentes en la clasificación durandiana, pero que se integran en la fundamentación de la Poética, en las dos posibilidades direccionales, transfusiva la una concentrativa la otra, del impulso mistico trascendente, registradas al analizarse su proyección expresiva.

Nuestra perspectiva sólo aparentemente contraría la clasificación básica durandiana, al reunir en una sola tendencia elementos de los dos Regimenes antitéticos: véase la rectificación del autor, contenida en el Anexo I, parte final del libro, donde unifica precisamente esas dos estructuras de regímenes diversos en una sola fuerza homogeneizante; "homogneizaciones por monopolización estereotipada de una sola estructura psíquica $/ . .$. " $^{\prime \prime}$

"Son homogeneizadoras las dos estructuras más excesivas, esquizomórfica y mística. La segunda, como ya nos pare- 
cía evidente en 1963, es fundamentalmente homogeneizante por "exceso" de homogeneización (y defecto inicial de distinción heterogeneizante) en las estructuraciones misticas (y más especialmente en las estructuraciones sobremisticas. . .); las primeras, a pesar de una apariencia heterogeneizante debida a la distinción, a la diéresis (o Spaltung) esquizomórfica, se saturan muy rápidamente y un fenómeno de inversión del sentido se produce: (Zerspaltung) equivalente a una homogeneización por falta, bastante notable en los protocolos imaginarios de los esquizofrénicos." (Anexo I, p. 504)

Significa que la expresión místico-poética incluiría en su unicidad, no sólo los elementos del Regimen Nocturno que Durand llama también inversión, intimidad, de su estructura mistica, sino también los elementos del Régimen diurno que se originan del impulso de evasión del tiempo hacia el nivel humano de la trascendencia, como dice el autor francés. Por otro lado San Juan de la Cruz es citado por Durand como ejemplo del dualismo antitético de las imágenes del Regimen diurno, y al mismo tiempo como ejemplo de la oscilación de valor negativo a valor positivo, caracteristica de lasimágenes del régimen nocturno, reuniendo en su inconmensurable riqueza creativa la ambivalencia de los dos regímenes: "asistimos a una inversión de los valores tenebrosos atribuidos a la noche por el régimen diurno" dice Durand al ilustrar sus afirmativas con el ejemplo del extraordinario simbolo sanjuanino de la "noche oscura".

Chez Saint Jean de la Croix, dans la si célebre métaphore de la "nuit obscure", on suit avec netteté l'oscillation de la valeur négative à la valeur positive accordée au symbolisme. Comme l'a indiqué E. Underhill, la "nuit obscure" a deux sens contradictoires et fondamentaux chez le poète du Cantique Spirituel. Tantôt elle n'est le signe que des ténebres du coeur et du desespoir de l'àme abandonnée, thème sur lequel Saint Thérese surenchérit, disant que l'âme est alors soumise aux fers et que ses yeux sont recouverts d'une taie épaisse. /. . . Tantòt, et c'est le sens prin. cipal que donne le célebre poème Par une nuit obscure, la nuit devient au contraire le lieu privilegiè de l'incomprehensible communion (. . .). D'autre part les poèmes de Saint Juan sont un bel exemple de l'isomorphisme des images du Regime Nocturne: la nuit est reliée a la descente par l'echelle sécrete, au deguisement, a l'union amoureuse, 
a la chevelure, aux fleurs, à la fontaine, etc. .." (249)

\section{"Gestos" poéticos y ảmbitos de lo poético.}

Asi como Durand estudia el "canevas" funcional de la imaginación, sus esqueletos dinámicos que llama esquemas, trayectos encarnados en representaciones concretas "presentificadores de gestos y pulsiones inconscientes" como dice citando a Sartre, nuestra Poética propone que el impulso de transcendencia - uno de los "gestos poéticos" o modalidades primordiales de la afectividad en su potencialidad dinámicocradora, de la emoción inspiradora del artista, - encarna como objeto literario en un peculiar sistema estilístico inscrito bajo el rótulo de "expresión mistico-poética". Esta representa así la refracción formal de una de las posturas fundamentales de la facultad poética, mientras todos sus temas como variada gama se despliegan entre una intencionalidad a lo trascendente extrahumano $y$ un impulso hacia la interioridad, temática que por engendrarse a partir de fuerzas de mismo signo se ordenará en el mismo ámbito de lo ontológicamente poético y de su proyección estilística, que bien pudiéramos denominar "género" de lo poético. Ya vimos que los procesos polarizantes de lo místico poético o del género trascendente - pueden aproximarse de las conductas antropológicas que desaguan, según Durand, por un lado en los esquemas ascensionales de su régimen diurno, y por otro en la estructura mística del "regimen nocturno", trayectos siempre motivados por imperativos de eludir tiempo, contingencia y muerte.

Otros dos ámbitos, a priori se delinean al lado del espacio de lo transcendente: el de una expresión actualizánte, con su impulso a registrar lo fenoménico que aparece al yo en su confrontación con el mundo, $y$ el de una expresión dinamizante de proyección activa en la modificación de ese mundo aparencial. En el terreno de la creación literaria, afirmamos, determinado impulso de penetración a lo absoluto, de transcendencia de lo aparente fenoménico, orienta la expresión hacia un ámbito estilistica y temáticamente configurado. De esta constatación se desprende que el proceso de creación poética se organiza hacia distintas regiones de caracteres estructuralmente centrados, pudiendo establecerse una morfologia clasificante del texto poético. Aunque este ensayo analiza una de estas regiones, previmos otros dos impulsos estructurantes más al lado del impulso de trascendencia: uno de subordinación a lo aparecial fenoménico, caracterizado por una expresión registradora del mundo, (donde se incluiria, por ejemplo, lo poético como "ornamento y amplificación de la vida y mundo" que en la palabra de Alberès se opone a la función o ejercicio poético como conocimiento del 
universo oculto, que este crítico estudia en el siglo $X X 1^{6}$ y otro impulso de organización o modificación de esse mundo, con una consecuente expresión dinámico-poética. Los impulsos dominantes se proyectan, hacia sus áreas propias, diferenciadas entre sí pero intrínsicamento homogeneas en la configuración formal: una relación entre lo afectivo-espiritual (aqui el anhelo de trascendencia) y la imaginación formalizante (el estílo literario, lo metafórico-simbólico) establécese naturalmente, en etapas de las cuales es punto de partida el anhelo vital, hacia lo imaginario en su representacion simbólica, para llegar al ámbito retórico (aquí la expresión místico poética).

\section{Aproximación metafísica y artística. Lo retórico.}

Entre las concordancias que hacen material del presente análisis, un campo esencial es el metafísico o ideológico, que en el proceso antropológico Gilbert Durand no deja de destacar, examinando la relación existente entre las sugestiones naturales de la imaginación y las actitudes morales o metafísicas - "ideales morales" y "completud metafísica". Asi, en la referencia ya vista a los simbolos ascensionales, verticalizantes derivados del esquema de la elevación, que según Bachelard son la metáfora axiomática por excelencia del vector vertical.

La búsqueda de la revelación, de alguna manera conectada a un infinito que nos trasciende, caracteriza la estructura poética en estudio. También para Durand la función fantástica tiene su "vocación ontológica" propia, una vez que lo imaginario constituye la esencia del espíritu, es decir el esfuerzo del ser para erigir una esperanza viva hacia $y$ contra la realidad de la muerte:

"Es la objetividad la que jalona y recorta mecánicamente los instantes mediadores de nuestra sed, es el tiempo el que distiende nuestra satisfacción en una laboriosa desesperación, pero es el espacio imaginario el que, al contrario, reconstituye libre e immediatamente en cada instante el horizonte y la esperanza del ser en su perennidad". (p. 435)

En esa "esperanza humana" a través de la proyección artistica, el ámbito poético de la trascendencia representa la fe en una revelación extrahumana, epifanía que solamente la palabra poética podrá recuperar. Durand, en las brillantes páginas de la Conclusión de su obra reafirma: "Tant il n'y a d'honneur véritable pour l'homme, que celui des poétes".

${ }^{6}$ ALBE RES, M. Bilain littéraire du XXè. siècle. Paris. Aubier, 1956. 
Aprehensión angustiante del devenir, reacciones ante el tiempo Jolorosamente efímero, deseo de eternidad que anhela anular el destino mortal mobilizan la máquina imaginante, así como el deseo de trascendencia - aspiración a un infinito, mobiliza el proceso creador, guiando la plasmación formal de texto literario: el anhelo de trascendencia es la directriz emocional, volitiva y metafísica que conduce a una categoría estructurada de la expresión. Entre el enfoque antropológico y el literario, una vez más se anuncia la coherencia del acercamiento, recayendo también en la motivación "ideológica" de las estructuras estudiadas.

Para nuestra poética de la trascendencia, las concordancias con Durand registran su esquema ascensional en tres manifestaciones imaginantes: ascensión a un más alla del tiempo, hacia un espacio metafísico del cual la verticalidad de la escalera o de la montaña sagrada, son símbolos corrientes, o el esquema del vuelo rápido, marca ascética o prototipo de una meditación sobre la pureza en las figuraciones del ala y la flecha. Cuanto a la semejanza en el "regimen nocturno" se sitúa en su tendencia a sintetizar "las aspiraciones al más allá de la trascendencia y las intuiciones inmanentes del devenir", cuando la noche no es sino propedéutica del dia, promesa indudable de la aurora", exactamente como en el símbolo sanjuanino.

Tales conductas antropológicas consisten, pues, en una reacción biofisica al perecimiento correlata de la reacción de angustia ante el fluir temporal, coincidiendo esa reacción biofísica con la fundamental motivación afectivo-espiritual y volitiva - volición agotada en el dominio imaginativo - con la tendencia o actitud axial de la estructura mistico-poética que es el ímpetu de trascendencia, el anhelo de penetrar mas allá de las apariencias, hacia un misterio intuido pero oculto al espíritu: entre el ansia de aprehensión de lo divino y le inmersión en las raices profundas del yo, la expresión mística también transfigura poéticamente los límites humanos y la incompletud del mundo, la búsqueda y la iluminación de un absoluto - el Tiempo, la divinidad, la esencia poética - , la revelación del misterio; el Ser o la muerte, intuiciones que acompañam al interior sondaje, la consciencia del yo frecuentemente percibido en instantáneas reminiscencias, o captado en la infusa idealidad de lo literario, inmersión poética que, como la actitud perfeccionante señalada por Durand, se manifiesta en instantes priviligiados en los que el artista "suspende el vuelo" del devenir, para reencontrar la esencia concreta de la eternidad:

Dans les beuax arts nous avons deja constaté combien ces structures mystiques étaient au fondement de toute une importante catégorie de moyens d'expression (. . .) Cette 
actitude perfectionante peut se manifester, comme nous l'avons dit, soit par les réalismes optimistes dans lesquels l'artiste' suspend le vol' des instants privilégiés, dans lesquels le souvenir proustien, l'égotisme des bons moments stendhaliens, la ferveur gidienne ou l'amour de la minutie chez Flaubert comme chez Van Gogh se rejoingnent, pour faire de ces instantannées du devenir l'essence mème de l'eternité retrouvée"'. (p. 489)

Porque considera todas las manifestaciones humanas de la imaginación, llega el antropólogo al fertilísimo campo de observación de la expresión artistica, siendo constantes en esta obra las aproximaciones a literatura y pintura. También al universo poético recurre Durand cuando debe aludir, por ejemplo, a la antítesis estructural del "régimen diurno" de la imagen, en cuyo dualismo ve un rasgo básico de "toda la literatura de occidente, irremediablement platónica", citando a Rougemont. Concordamos en que caracteriza, si, toda literatura fundada en una poética de lo trascendente. Con respecto a la imagen literaria, Durand nota que "el psicólogo se asombra ante el carácter de rigor universalizante de las imágenes ligadas a esquemas de ascensión y des censo, y por comparación encuentra esas coincidencias en la obra de Dante y en la poesia de Victor Hugo, comprobando, en este poeta francés la polarización constante de siete categorías de imágenes que parecen, por su convergencia, definir una estructura de imaginación".

En este trayecto de su investigación, no es de extrañar que se detenga Durand en el concepto de retórica: el "eufemismo de la fantasia" aparece fundamental en el fenómeno humano, aunque nuestra óptica particularista de objetividad civilizada lo vea insólito; la comprensión antropológica, em cambio, no puede menos que exaltar a lo imaginario:

"Notre civilisation rationaliste et son culte pour la démistification objective se voit submergée en fait par le ressac de la subjetivité brimée et de l'irrationnel" (p. 495).

Durand propone, inclusive, la rehabilitación de la retórica para el pleno acceso a lo imaginario, a fim de recolocar la obra de arte en su lugar antropológicamente conveniente. Al referirse el autor al pasaje de proyección imaginaria a expresión estilistica, ve que se trata de un proceso de esquematización, en el cual el resultado final, la figura expresiva o la retórica, nacen de la transposición del semantismo vivenciado en la inspiración profunda de la fantasia a puro procedimiento semiológico, formal, al signo o a otros recursos de mayor elaboración formali. zante. La cualidad dominante de la retórica es transcribir un significado 
por medin de un significante, transcripción que consiste en la degrada. ción del semantismo de los símbolos. Lo semiológico sólo tiene valor por referencia, antes, a lo estilístico, y después, al semantismo, y no lo inverso; asimismo, la palabra sólo es real porque es vivida en un contexto expresivo, comprometida en un papel metafórico. En el esquema de la poesía contemporánea trazada por $M$. Alberès, se encuentra sin duda delineado el ámbito de la trascendencia poética. Refiérese el autor a una génesis de la concepción poética del siglo $X X$, que caracteriza como una "aventura del poeta en el dominio del conocimiento", cuando el ejercicio poético se identifica con una búsqueda y con un credo, búsqueda de un conocimiento secreto, testimonio de una verdad oculta que confronta al poeta con el Absoluto que lo trasciende, o creencia de que existe tal verdad. El poeta la alcanza, dice Alberès, por una "iluminación" hecha de exaltación del espiritu y de la sensibilidad en sus anhelos extrahumanos. La correspondencia entre sensibilidad, imaginación y ciertos ritmos secretos del universo que ni la observación común ni la científica cuidan captar, es una forma de la procura exasperada de absoluto que aqueja a los poetas. ${ }^{8}$ Esta conexión de la poesía y de la revelación, diverge, en el panorama literario contemporáneo, de la prosa novelesca, centrada antes en objetivos sobre todo morales, cuanto a la conducta y al comportamiento humanos. La poesía no narra, no analiza una conducta ni propone ideales o ideologías, sino que nace de un contacto mágico entre una sensibilidad y el universo, buscando su conocimiento profundo., en conceptos inefables que debe expresar en el limitado lenguaje humano. "La obra contemporánea es asi, casi siempre, un desafio para el poeta: el de expresar en el insuficiente lenguaje humano sus experiencias indecibles, precisamente aquello que es inaccesible a la lógica del lenguaje humano". ${ }^{7}$ El objeto de tal literatura es invisible, un valor intemporal, una suma de la existencia que sólo podría cristalizar en un medio que no sea la existencia.

Asi llega Alberès a esbozar una caracterización indirecta de las formas poéticas de lo trascendente, por oposición a las que no lo son: de un lado, la poesia-ornamento de un universo común a los hombres, amplificación de la vida, poesía centrada en el lirismo, en lo pintoresco o en el verso; que cultiva los temas y formas tradicionales, referidos a sentimientos generales, a descripciones exactas, a narraciones objetivas, y tambièn a la meditación o la exaltación del sentimiento, $y$ aun al juego de emociones o sensaciones en sí mismas centradas, o basadas en un esoterismo superficial y decorativo: de otro lado, la poesia - ilumi-

\footnotetext{
ALBE RES.

"En su interesante ensovo. Alberès situa cronologicamente esta poesla desde la famosa definıción de Mallarmé (1886): "lo poésie est l'expression par le langage humain ramené a son rhvthme essentiel du sens misteribux :'es uspects :de l'existence" (Alberès sublina) has ta hov.
} 
nación, técnica peculiar para descubrir la faz oculta de su universo, su mundo sobrerreal.

Esta poesia que visa lo trascendente es para Albères definitiva en su proyección histórica: "II reste peu vraisemblable que change le destin de la poésie". Pues se ha transformado en el substituto de una vida espiritual para los seres marcados por la necesidad de trascendencia, a quienes no satisface una regla religiosa. La poesía permanecerá, dice el crítico francés, la expresión de impulsos extrahumanos, y esta génesis poética es a la vez la más profunda y la más definitiva: el mundo contemporáneo no es más propicio a una poesía decorativa, rechazando a los rimadores placenteros y conmovedores, y aun a una inspiración esotérica sin motivaciones profundas. Cuando el deseo de Absoluto no es satisfecho por una mística o por una teología comunes, la poesía resulta ser el único medio de acceso a un mundo mágico, para todos aquellos que viven la nostalgia de tal mundo.

\section{Poética de la trascendencia y "epifania".}

Cuando ciertos etudios literarios se proponen analizar la epifanía (por definición "entrada", "aparición", y por extensión "la súbita revelación de la verdad") se aproximan evidentemente al ámbito de la trascendencia poética. En su estudio "A epifania, como eixo convergente da escritura de Günter Eich e Clarice Lispectos", Eloá di Pierro Heise examina a los autores-titulos como escritores que "en una constante indagación metafísica buscan desvendar el misterio perenne del hombre y del mundo". 9

El enfoque analitico de ese estudio se aproxima a las bases criticas sobre las cuales se fundamenta la Poética de la trascendencia, y su caracterización de la epifania como experiencia y como proceso que se inscribe en la escritura poética, presenta concordancias con el mismo proceso motivador de la expresión mistico-poética. La primera coincidencia a destacar la más comprehensiva, es la que se refiere a las premisas metodológicas del análisis, destacada por Heise cuando se propone tratar "os textos dos dois autores como componentes de uma obra poética total, como um único modo de captar e tentar desvendar o mundo", pues "ambas escrituras, mais que dois textos convergentes, calificam uma modalidade do literário (Subrayado nuestro). Y también." "Pretendemos mostrar o que há de especifico nas modalidades epifánicas de cada um". A esta "modalidad", a su caracterización en el panorama total de la expresión poética, a su proyección taxinómica

${ }^{9}$ HEISE, E. P. A epifania como eixo convergente da escritura de Gürter Eich c Clarice Lispector. Humboldt (41):50.3, 1980. 
como "gesto" o como "género", de lo poético, a las justificativas teóricas y metodológicas de su formulación está destinada la Poética de la trascendencia, es decir, ambas obras unificándose en un único ámbito de la expresión aquí calificado como "epifánico". Derivada de esta concepción es la evidencia de inutilidad de la estructura "género literario": "A divisão em generos, no caso deste trabalho, fica reduzida a mero preconceito", y que consignamos en nuestra tesis La expresión místico-poética en Alberti, Jiménez y Cortázar citando el criterio del mismo autor-título analizado, cuando afirma: "Más allá de las artificiales fronteras entre prosa y poesía, géneros literarios y otras clasificaciones limitadoras, está (. . .) un estado de intuición para el cual la realidad, sea cual fuere, sólo se revela poéticamente. (. . .) Abolida la frontera preceptiva de lo poemático y lo novelesco, sólo un prejuicio que no es ni será fácil superar (máxime cuando las corrientes genéricas tradicionales continúan imperturbables $y$ se cumplen en manifiesta mayorial, impide reunir en una sola concepción espiritual y verbal empresas en apariencia tan disímiles como The Waves, Duineser Elegien. Sobre los ángeles, Nadja, Der Prozes, Residencia en la tierra, Ulysses y Der Tod des Virgil:" (p. 141) También esta única concepcion espiritual y verbal a que alude Cortázar es la que justifica la génesis de la teoria propuesta en la Poética de la trascendencia.

En semejante perspectiva metodológica, aunque sin llegar a una abstracción teorizante que transbordaria los objetivos y las dimensiones de su artículo, Eloa Heise tiende un puente entre el lenguaje de ambos autores hacia su significación ontológica.

El cuestionamiento del propio lenguaje como instrumento ontológico, la evidencia de su defectibilidad cuando se trata de traducir un indecible, permanece también una constante del discurso crítico de la epifania. El artículo tiende a mostrar cómo los dos escritores abordados se muestran fundamentalmente comprometidos con la procura del ser bajo forma de lenguaje:

"A escritura dos dois poetas, na sua busca pelas essencias, 'inexprimindo o exprimível', agrupa palavras e frases das quais evola um sentido secreto que as ultrapassa e as transmuta." "Nos dois autores, os conceitos de tempo e linguagem,/. . . / levam à concretização de momentos epifânicos." 10

Asi, la epifanía como experiencia y como revelación surge del proceso creativo incidente en el lenguaje poético:

\footnotetext{
${ }^{10}$ HEISE, (1). 52.

Letras, Curitiba (33) 163-179 - 1984 - UFPR
} 
"Para Eich, epifanía implica um processo de criação, portanto muito mais operativo, de buscar constantemente a revelação do real". "O autor está empenhado em constituir, através da instrumentalidade de sua linguagem, o real, já não em reproduzí-lo segundo os conceitos existentes. Visando a um foco transcendente, a linguagem do autor lança-se a uma permanente renovação, premissa fundamental para a coerência da própria busca"."

Finalmente, la epifanía según menciona para los casos de Clarice y de Eich, también se encamina en su expresión hiacia ciertos procedimientos estilisticos que se forjan al constituirse el lenguaje fuera de los padrones lógicos enumerados en nuestra obra La expresión mistico poética en Alberti, Jiménez y Cortázar, "contrastes e analogías", "oximoros e paradoxos, comparações e metáforas", en Clarice Lispector, $y$ en Eich, la "apreensão da realidade por via analógica, a através de imagens, e figuras como recurso poético essencial" que aspira a designación pura, a la plenitud del significado.

Las alusiones a la experiencia epifánica que viven los personajes son frecuentemente coincidentes con la experiencia extática tal como se la analiza en la expresión mistico-poética. Ocurre en ella la "anulação de fronteiras entre o sujeito e o objeto" y sobre todo la anulación de la temporalidad: "O instante banal consegue a suspensão do tempo cronológico e cristaliza a realidade. A epifania representa, assim, um momento de visão que sem ser explicado racionalmente, surge como fonte de revelação." La instantaneidad y la fortuidad, el aporte de revelación de la experiencia extática se reconocen en total coherencia:

"O nada e o tudo podem acontecer em um momento inesperado. E nesse momento percebe-se o sentido de uma revelação em aberto. Num instante de atemporalidade podem se roçar os limites de uma outra realidade trascendente, mas esses contatos que chegam a ocorrer por segundos, são novamente destruídos. Retorna-se à busca infinda, e à subordinação ao "processo". O caminho que leva à verdade e à revelação é uma experiência individual, interior e inexplicável $(. .)^{12}$

Aun reconociendo que "As obras representariam um testemunho de um estranhamento diante da realidade. . . tornando-se paradoxalmente um instrumento poético de busca do real"', uma constante pro-

11 HEISE; p. 51.

12 HEISE, p. 52. 
cura de revelação e conhecimento", también se alude a los límites de la concretización epifánica, que puede consistir, para algunos escritores (Lispector), en um proceso que nunca alcanza la definitiva llegada, la revelación total: "Algo sempre foge na concretização plena da verdade, apesar de que por instantes se vislumbre uma possibilidade de encontro, projetada insistentemente através de visões epifânicas."

La ocurrencia de la epifanía sería, en ese caso, sólo un acercamiento a la revelación, sea por caminos arracionales - como para Lispector -, sea por un proceso operativo de busca - como para Eich - : "Depois de ter vivenciado por segundos a súbita revelação da verdade, a personagem busca reviver este instante de plenitude."

\section{REFERẼNCIAS BIBLIOGRÁFICAS}

1 ALBERĖS, M. Bilain littéraire du XXè. siècle. Paris, Aubier, 1956.

2 DURAND, G. Les structures anthropologiques de l'imaginaire. Paris, Bordas, 1969.

3 HEISE, E. P. A epifania como eixo convergente da escritura de Günter Eich e Clarice Lispector. Humboldt (41): 50 - 3, 1980.

4 SOIFER, M. La expresión místico-poética en Alberti, Jimenez y Cortázar. Curitiba, 1977. Tese, Titularidade, Universidade Federal do Paraná.

5 - La expresión místico poética: Valéry y San Juan de la Cruz Curitiba, Editora da Universidade Federal do Paraná, 1983. 